\title{
Las pruebas de usabilidad e interfaz audiovisual en la película interactiva Arthur 2.0.
}

\section{Usability Test and Audiovisual Interface in Arthur 2.0 Interactive film.}

TIPO DE TRABAJO:

Comunicación.

PALABRAS CLAVE:

Diseño de Interacción, interactivo de la película, la interfaz audiovisual, pruebas de usabilidad, experiencia de usuario UX.

KEY WORDS:

Interaction Design, interactive film, audiovisual interface, usability testing, UX user experience.

\section{RESUMEN.}

La investigación trata del diseño de interactividad de la película interactiva Arthur 2.0, realizada en conjunto con Péricles Silveira, coautor de la película. Se examina, a partir del diseño de interacción, uno de los 6 momentos de interacción entre el interactor y el diseño de interactividad de la película, instantes llamados de Momentos Interactores (MI). El objetivo es verificar si la interface de la película realiza con eficiencia las tareas para las que fue proyectada: hacer con que el plano de la película, en esos momentos, sea el más neutro posible y las elecciones en la película expresen los deseos del interactor y no de la interface. El abordaje envolvió recolección de datos utilizando métodos y técnicas que incluyeron la observación directa y el empleo de entrevistas con el público en 3 ambientes diferentes - jóvenes entre 16 y 27 años y adultos entre las franjas de 28 a 37, 38 a 47 y 48 a 68 años. ¿Qué relación existe entre el color preferido y los elementos que llaman la atención en una película? ¿Los elementos que llaman más la atención son las partes de las imágenes de una película más cautivantes que envuelven el espectador? Son algunas consideraciones que el trabajo hace a partir de este estudio.

\section{ABSTRACT.}

The research deals with the interactivity design of the interactive film Arthur 2.0, made in conjunction with Pericles Silveira, co-author of the film. From the interaction design, one of the 6 moments of interaction between the interactor and the interactivity design of the film, called moments of Interacting Moments (MI), is examined. The objective is to verify if the interface of the film efficiently performs the tasks for which it was projected: to make the plane of the film in those moments as neutral as possible and the choices in the film express the wishes of the interactor and not the interface. The approach involved data collection using methods and techniques that included direct observation and the use of interviews with the public in 3 different settings - youngsters between 16 and 27 years and adults between the ranges of 28 to 37,38 to 47 and 48 to 68 years old. What is the relationship between the favorite color and the elements that attract attention in a movie? Are the elements that attract the most attention the most captivating parts of a movie that envelop the viewer? They are some considerations that the work does from this study. 


\section{CONTENIDO}

\section{Introducción.}

El tema de esta investigación trata de la prueba de diseño de interacción de la película Arthur 2.0, realizada en conjunto con Péricles Silveira, coautor de la película. El estudio examina uno de los 6 momentos de interacción entre el interactor y el diseño de interactividad de la película en destaque, instantes que llamamos de Momentos Interactores (MI). La intención es verificar si la interface de la película ejecuta eficazmente la tarea para la cual fue proyectada: hacer con que el plano de la película, en esos momentos, sea el más neutro posible y que las elecciones en la película expresen los deseos del interactor y no de la interface.

El abordaje envolvió tres de los principales métodos de recolección de datos más usados para estas pruebas de diseño de interacción: entrevistas, cuestionarios y observación directa. En el caso de la observación directa, adoptamos un papel de observador externo, pasivo, sin interferir en la conducción de las entrevistas. Utilizamos el estilo de entrevista estructurada con preguntas cerradas, porque no era intención, en este caso, que el entrevistado saliese del foco del problema. Las preguntas, así, fueron bien direccionadas para los propósitos de la entrevista, salvo la última pregunta en la que empleamos el estilo de entrevista semiestructurada, o sea, la combinación entre los estilos de entrevista estructurada, con preguntas cerradas y el estilo no estructurado, con preguntas abiertas. A pesar de la abertura, esta cuestión resaltada impone límites, he aquí a seguir la pregunta que es un caso de excepción: "¿Le gustaría agregar algún otro detalle que considere importante?". La pregunta es esencialmente neutra, funciona como un sondeo y solicita que el entrevistado recuerde, o no, de algo no tratado en la entrevista o que haya olvidado durante su realización. La abertura de esa cuestión, infelizmente, no contribuyó efectivamente para la investigación, pues casi 100\% de los entrevistados respondió que no había nada a agregar además de las respuestas anteriores.

Las entrevistas fueron realizadas en la región de la Avenida Paulista, en São Paulo, en el Conjunto Residencial de la Universidad de São Paulo (CRUSP) y en un cinema tradicional de calle de la ciudad: Itaú Cinemas, de la calle Augusta (ambiente principal y anexo). La intención era incluir en la investigación además de los cinéfilos - como los encontrados en el cinema nombrado, estudiantes universitarios y el público de calle que circula abundantemente en las áreas de las salas de cinema, como en el caso de la Avenida Paulista.

Para la realización de las entrevistas utilizamos cuestionarios impresos en papel y las escenas de la película fueron visualizadas en un smartphone Samsung Note 5 de 5.7 pulgadas. Las franjas etarias, de los entrevistados fueron divididas en 4 grupos de edades segmentadas entre jóvenes de 16 a 27 años, y adultos de 28 a 37 años, de 38 a 47 y de 48 a 68 años.

Antes de presentar el tema central de esta investigación - análisis de datos de los cuestionarios - vamos a tratar resumidamente de proposiciones de la película Arthur 2.0 que son fundamentales para comprender los datos tratados: El guión de la película y el diseño de interacción.

\section{Arthur 2.0 y el Diseño de Interacción.}

El guión de la película es compuesto de tres líneas narrativas principales. Una llamada enfoque amoroso; la segunda línea llamada enfoque proyecto y la última denominada enfoque proyecto $A$. La historia es contada desde el punto de vista del personaje Arthur y muestra su jornada de trabajo y/o amorosa a partir de sus inquietantes y profundos recuerdos; desvenda lo que él piensa o imagina sobre su jefe Miranda, su novia Fernanda y Daliton. Arthur, el narrador de la historia, intenta convencer al interactor de que su punto de vista es la verdad.

Arthur tendrá un día difícil y él hará lo imposible para que su jornada sea la mejor. El interactor podrá ayudarlo en esa tarea. Para eso, basta que sus ojos, en momentos específicos de decisión en la narrativa, coincidan con el área de la imagen (A o B) que lleva a Arthur a un desenlace positivo [il. 1]. 


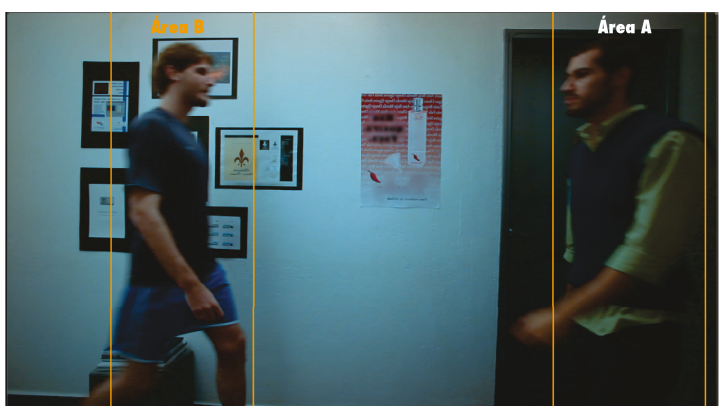

Ilustración 1

Esos momentos denominados de MI - Momento Interactor ocurren en 6 instantes de la narrativa. Para obtener más detalles sobre los MI, véase el artículo Agencia y diseño de interactividad de la película Arthur 2.0 (CÂNDIDO TAVEIRA, 2015: 138 - 145).

Los MI en la película suceden en las escenas 3, 4, 7, 13, 21 y 27. Véase los círculos en azul oscuro en el diagrama de flujo del guión [il.

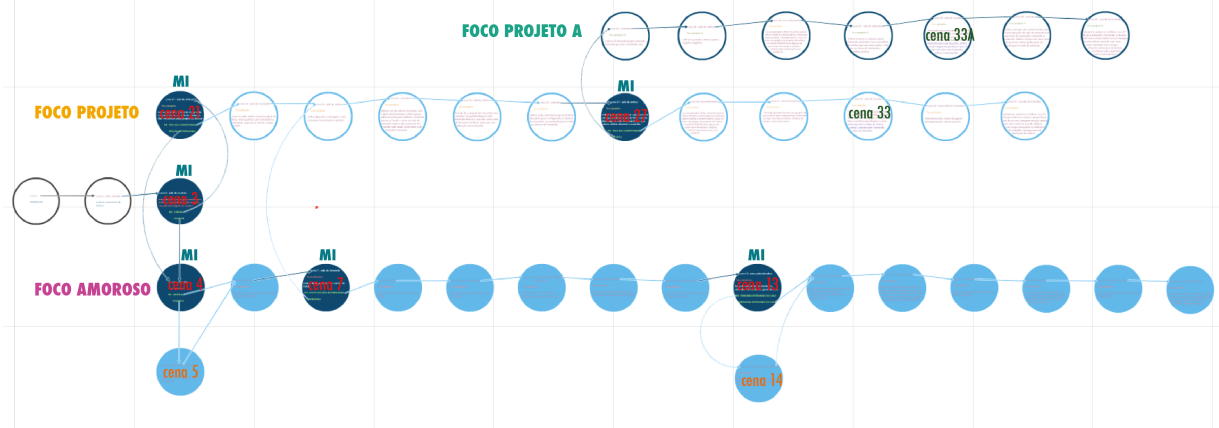

Ilustración 2

2]. En eses escenas, en algunos instantes, los planos de la imagen tuvieron una découpage especial. Fueron planeados llevando en cuenta el desplazamiento y el tiempo de mirada empleado por el interactor en la lectura de las informaciones en la pantalla en las áreas A y B de la imagen [il 1]. Aquí trataremos apenas la escena 3.

Las entrevistas realizadas examinaron exactamente esa cuestión e intentan solucionar los problemas e planeamiento de las imágenes. La intención es dejar los planos de esos instantes de elección en la película lo más equilibrados y neutros posible. El propósito es que la toma de decisión sea la más próxima al deseo del interactor y no al de la interface de interacción. La duración del tiempo de mirada del interactor sobre una de las áreas del plano determina el desencadenamiento narrativo de la escena siguiente. El mayor interés o deseo en un área específica del plano irá instaurar una toma de decisión, aunque inconsciente, del interactor. Si los ojos del interactor, por ejemplo, siguen al personaje del área B por 4 segundos y acompañan por 6 segundos al personaje del área A, la escena siguiente tendrá como eje dramático las acciones del personaje del área A [il. 1].

\section{Datos demográficos. Consideraciones preliminares.}

Las entrevistas fueron realizadas a 20 participantes e involucraron la población cinéfila de 16 a 68 años, dividida en 4 franjas etarias. Para el muestreo no discriminamos cinéfilos y no cinéfilos, el foco era el público adulto en general. La intención inicial era realizar 100 entrevistas, pero en las diez primeras verificamos que no era necesario efectuar tal número, dado que habían apenas dos posibilidades, o mejor, dos áreas de visualización de la imagen de prueba, el área A y el área B [il. 1]. Inferimos que un muestreo de 20 participantes seria bien representativo para el objetivo de investigación: verificar cuales objetos, colores y sonidos en esas áreas (A y B) llaman la atención del espectador, es decir, averiguar la percepción que tiene sobre esas imágenes y certificar si el diseño de ese momento de la escena es neutro y equilibrado. 
Las preguntas fueron todas efectuadas en la secuencia como sigue a continuación. Pero, antes de aplicar los cuestionarios, se le contaba al entrevistado un poco sobre el proyecto y el guión de la película, sin nunca tratar sobre contextos de las escenas. Ese fue el procedimiento aplicado en todas las entrevistas: el entrevistado visualizaba el trecho de la escena y a continuación realizábamos las preguntas.

Lo que percibimos es que todos los entrevistados, sin excepción, se asustaron al asistir la primera escena. Imaginaban una escena larga, pero los trechos exhibidos duraban en promedio 10 segundos. La primera reacción era la de sorpresa, susto. No esperaban una duración tan corta. Algunos se sintieron hasta coaccionados por miedo a no recordar lo que responder sobre lo que acabo e asistir. Oriente a todos que no era necesaria esa preocupación y así las entrevistas transcurrieron en un ambiente y clima más tranquilos. Cada entrevista duró entre 20 y 25 minutos.

Preguntas aplicadas después de la exhibición del trecho de la escena 3:

¿Cuál es su color preferido?

¿Ese color aparece en la escena que acabo de ver?

Si la respuesta fue SI, ¿¿cómo aparece su color favorito en la escena?

¿Qué sucede en la escena?

¿Qué le llamo más la atención en la escena?

¿Utilizó más tiempo mirando para que parte de la escena?

¿Por qué?

¿Qué hacen los dos personajes sentados en la mesa?

¿Qué hace el personaje en el centro de la imagen?

¿Le gustaría agregar algún otro detalle que considere importante?

La población entrevistada es relativamente equilibrada en relación a género, formada por $55 \%$ de género masculino y $45 \%$ de género femenino [il. 3]. No hubo ninguna referencia a otro género.

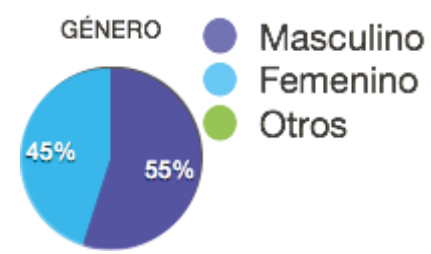

Ilustración 3

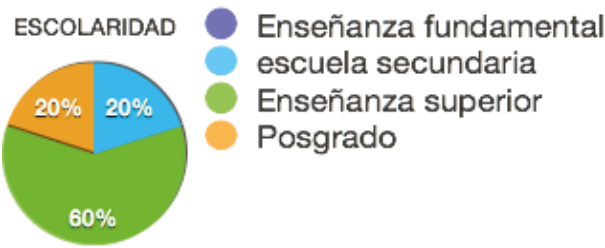

Ilustración 4 
En relación a la escolaridad el público es variado, formado por entrevistados desde educación secundaria a post-graduación. $20 \%$ afirmaron tener educación secundaria y otro $20 \%$ declararon tener post-graduación. Mayoritariamente el público es constituido por personas con título de educación superior: $60 \%$ [il.4]. Nadie declaro tener solo educación fundamental.

$27 \%$ de los entrevistados revelaron que van a cine una vez cada 6 meses; $27 \%$ frecuentan una vez por mes. $47 \%$ van a cine una vez por semana [il. 5].

\section{ASISTENCIA AL CINE}

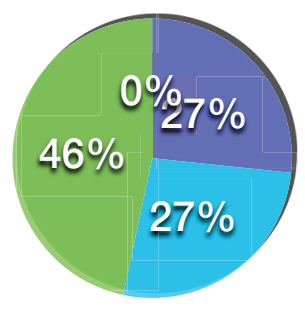

Una vez cada 6 meses

- Una vez al mes

- Una vez a la semana

Tres veces por semana

\section{Ilustración 5}

\section{Mapeando deseos y apuntes para reconfiguración del diseño de interacción. Momento Interactor - Escena 3.}

Para verificar si el découpage de la escena 3 de la película dejo la imagen equilibrada o no, hicimos la siguiente pregunta a los entrevistados: ¿Qué fue lo que le llamo más la atención en la escena? Véase a seguir en las llustraciones 6 y 7 las áreas y objetos que más causaron impacto, conforme el conjunto de entrevistados. $21 \%$ afirmaron que el área A fue la que más les llamo la atención, esto es, el área en que los dos personajes más jóvenes, sentados en la mesa, intercambian mensajes por celular. El pop-up en el área A fue recordado, aparte, por $17 \%$ de los entrevistados. La pareja sentada en la mesa, en el área A, fue citada por un $3 \%$. Un detalle: ninguna referencia directa al personaje femenino; $3 \%$ no recuerdan o que les llamo la atención, y nada llamo la atención de $3 \%$ de los entrevistados.

Ya el área B causo más impacto para $24 \%$ de los entrevistados, $3 \%$ más que los del área $\mathrm{A}$. El panel en el centro de la imagen, en el área B, fue citado en $10 \%$ de las respuestas. El personaje de pie, citado por los entrevistados como "presentador", llamo la atención para el 10\%. El traje del mismo personaje fue recordado por 3\%. Lo más sorprendente y precioso de esta investigación es en relación al pañuelo rojo del personaje, del cual no hubo ninguna referencia. Durante el planteamiento de la imagen era exactamente este elemento que temíamos que fuese el más recordado por lo llamativo del color. El azul de la escena fue recordado por el $3 \%$.

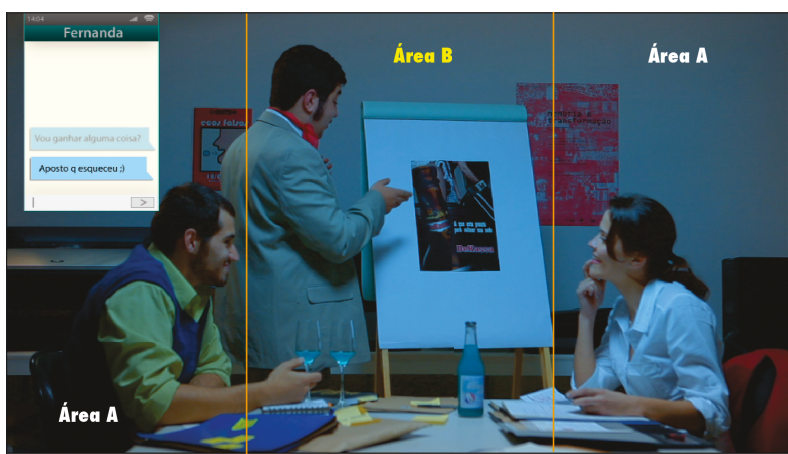

Ilustración 6 


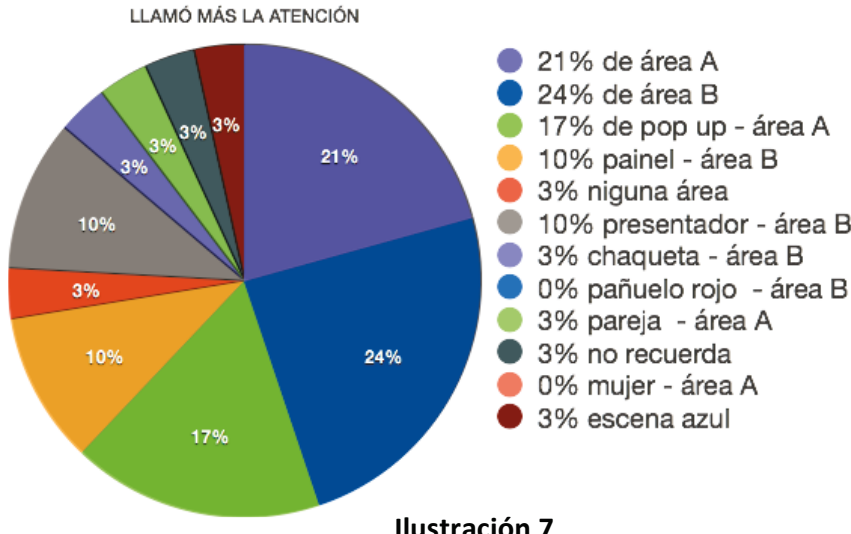

Ilustración 7

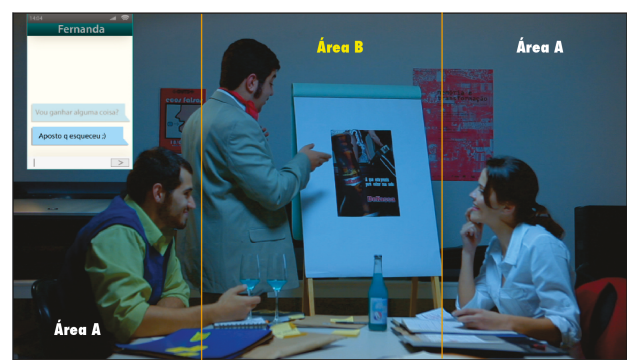

Ilustración 8
MAYOR TIEMPO DE FIJACIÓN DE LA MIRADA

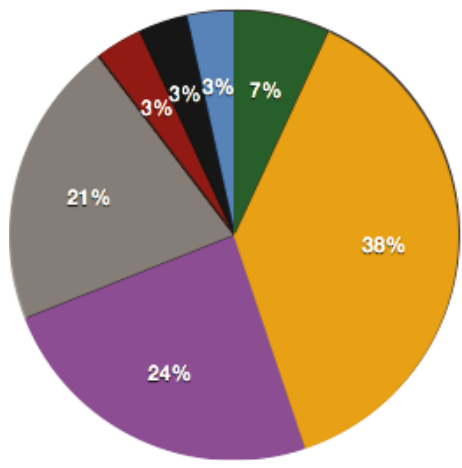

Ilustración 9
$7 \%$ de área $\mathrm{A}$

$38 \%$ de área $B$

$0 \%$ de pop up - área $A$

$24 \%$ painel - área B

$0 \%$ niguna área

$21 \%$ presentador - área $\mathrm{B}$

$0 \%$ chaqueta - área B

$3 \%$ pañuelo rojo - área B

$3 \%$ pareja- área A

$0 \%$ no lo recuerda

$3 \%$ mujer - área $\mathrm{A}$

$0 \%$ escena azul

Para examinar se había una relación directa entre las áreas que más llamaron la atención de los entrevistados y las áreas en que los mismos utilizaron más tiempo viendo la escena, formulamos la siguiente pregunta: ¿ Utilizó más tiempo mirando para que parte de la escena? Lo sorprendente es que las áreas que más llamaron la atención no fueron las que más tiempo los entrevistados gastaron viendo la escena. El área $\mathrm{A}$ inesperadamente fue citada apenas por $7 \%$ de los entrevistados. Un detalle: La misma área $\mathrm{A}$ llamo la atención para el $21 \%$. Otro dato imprevisto, no hubo siquiera una referencia al pop-up del área A. No olvidar que la misma área llamo la atención del $17 \%$. Lo que podemos inferir a partir de esos datos es que esas áreas apenas llaman la atención, pero no son suficientemente cautivantes o envolventes para tener una experiencia mayor con el interactor o espectador. Aún en el área A, solamente $3 \%$ de los entrevistados confirmaron que miraron más tiempo para la pareja e igualmente $3 \%$ para el personaje femenino.

En relación al área de mayor envolvimiento con la imagen el destaque es el área B, 38\% confirmaron que se envolvieron más con el área en énfasis [il. 8-9]. Un detalle: La misma área llamo la atención del $24 \%$ de los entrevistados. Otro detalle importante: Otras dos porciones de la imagen, en el área B, son igualmente cautivantes: El panel y el personaje de pie (el "presentador). Ambas porciones pasaron de $10 \%$, cada una de ellas, para $24 \%$ y $25 \%$ respectivamente (il. $8-9$ ]. El pañuelo rojo que no llamo la atención fue la franja que envolvió $3 \%$ de los entrevistados.

Lo que podemos concluir, basados en los datos, es que hay un grande desequilibrio en el planteamiento de las imágenes de la escena 3: $86 \%$ de los entrevistados gastaron más tiempo mirando para esa área de la imagen. Del punto de vista de los propósitos de la película, el diseño de interacción es un grande problema: la narrativa tiende $86 \%$ a seguir siempre la misma opción. Apenas $14 \%$ de posibilidades para avanzar para otra opción. El área B necesita involucrar menos el interactor para dejar el plano de imagen más neutro. 
Otro dato importante: $75 \%$ de los elementos de la imagen en el área A llaman mucho la atención, pero apenas $25 \%$ de los elementos de la imagen son cautivantes. En el área B apenas 39\% del área causan impacto, mas por otro lado $61 \%$ del conjunto del área envolvieron a los entrevistados [il. 10-11].

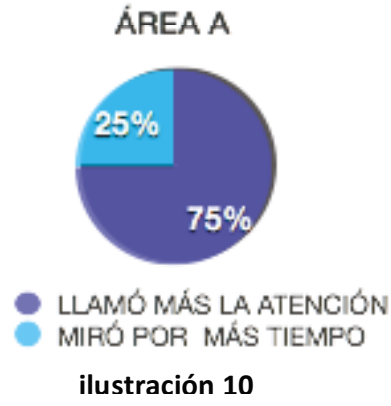

ÁREA A

ilustración 10

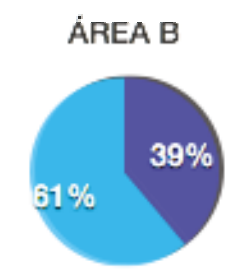

lLamó más La atención

MIRÓ POR MÁS TIEMPO

ilustración 11

\section{Correspondencia entre color favorito y envolvimiento con las imágenes. Consideraciones iniciales.}

Al examinar si había alguna correspondencia entre el color favorito del entrevistado y lo que más le llamo la atención de la escena (il.12), formulamos las siguientes preguntas: ¿Cuál es su color favorito? ¿Ese color aparece en la escena que acabo de ver? Para nuestra sorpresa la gran mayoría de los entrevistados simplemente no recordaba si vio su color favorito en la escena. $20 \%$ cree que no aparece; $20 \%$ cree que sí, pero no está seguro; $27 \%$ no recuerda y $33 \%$ afirma que su color favorito estaba presente en la escena (il. 13). Una observación: 5 entrevistas no entraron en los datos en cuestión, porque los entrevistados o no tenían un color predilecto o tenían muchos, por lo cual encontramos adecuado no incluirlos en esta muestra.

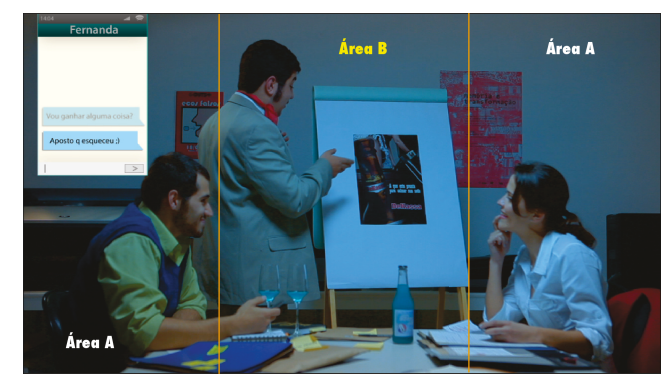

Ilustración 12

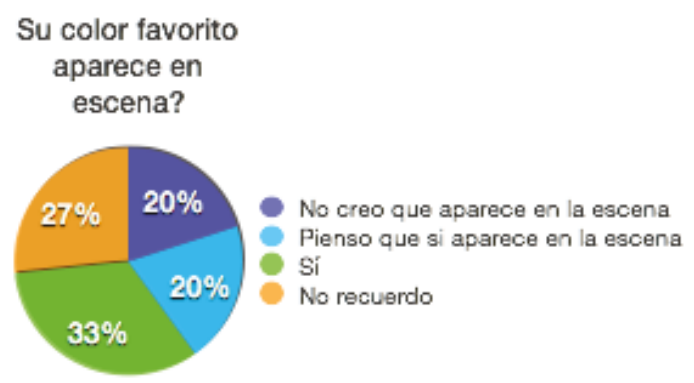

Ilustración 13

Otros datos relevantes: del 33\% (il. 13) que afirmaron que su color favorito estaba en la escena, el 20\% optó por el negro, $40 \%$ por el verde y $40 \%$ el rojo (il. 14). Se destaca que la escena (il. 6) esos tres colores están presentes: el color rojo aparece en los carteles pegados en la pared y en la pañuelo rojo del personaje que esta de pie, el verde en la camisa del personaje sentado en la mesa y el negro en el cabello de los personajes.

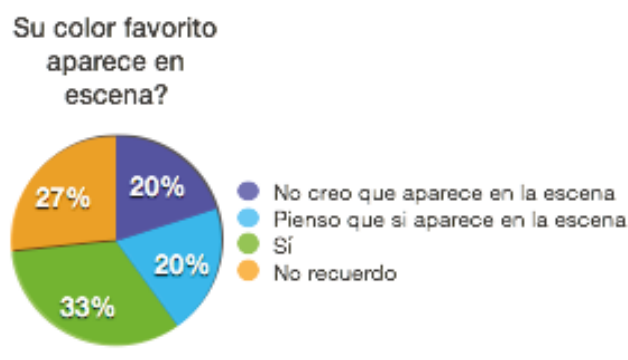

Ilustración 13

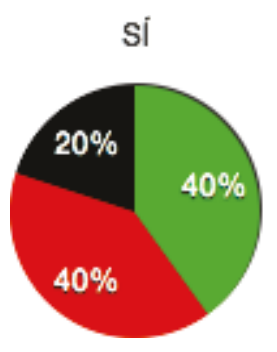

Ilustración 14 
Otro grupo de entrevistados, aunque coincidiendo con la predilección de color del grupo anterior (il. 13), cree que esos colores no aparecen en la escena (il. 15).

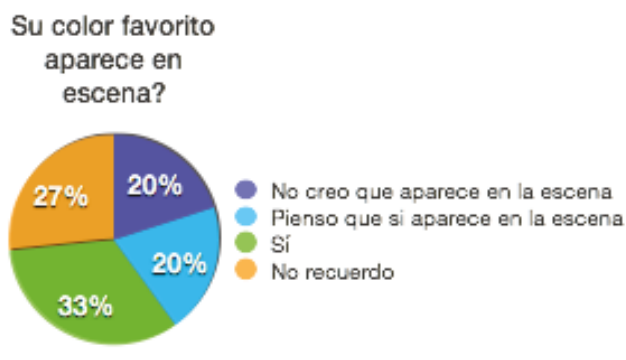

Ilustración 13

\section{NO CREO QUE APARECE EN LA} ESCENA

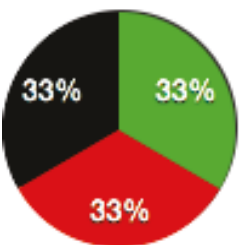

Ilustración 15

Del grupo de $20 \%$ de los entrevistados (il. 13), que cree que si, su color favorito está en la escena, pero no está seguro, $33 \%$ opta por el verde como favorito y $67 \%$ por el azul (il. 16). Los dos colores también están en la escena, véase ilustración 12.
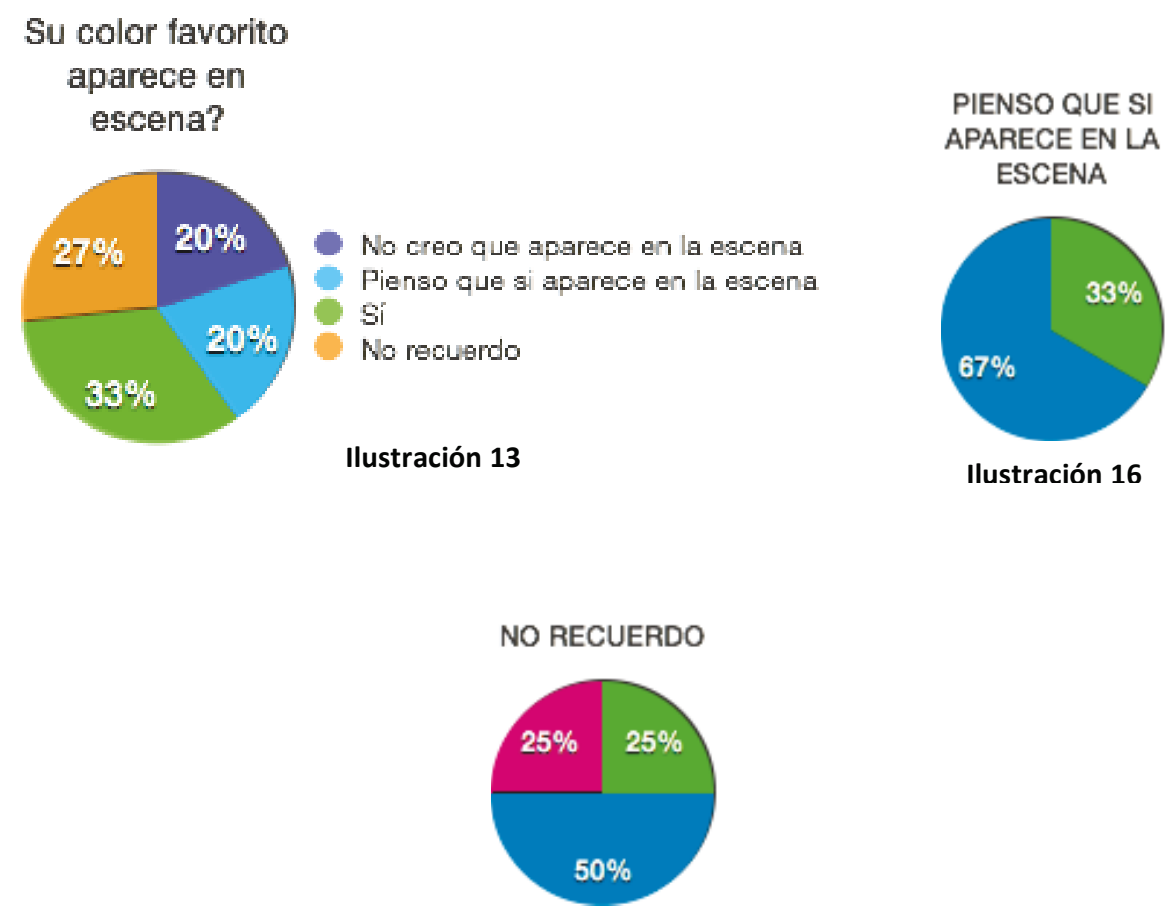

Ilustración 17

Para finalizar, del grupo del $27 \%$ de entrevistados (il. 13), que afirmaron no recordar si su color favorito estaba en la escena, $25 \%$ opta por el color púrpura, $25 \%$ por el verde y $50 \%$ por el azul (il. 17) Solamente el púrpura no está en la escena (il. 12).

No es posible afirmar si existe una relación directa entre el color favorito y el objeto de atención de la escena, porque la gran mayoría de los entrevistados no recuerda se lo vio o no. 


\section{FUENTES REFERENCIALES.}

BORDWELL, David. Narration in the Fiction Film. Madison, Wis: University of Wisconsin Press, 1985.

CÂNDIDO TAVEIRA, Maurício. Agencia y diseño de interactividad de la película Arthur 2.0 in: Real/Virtual, II ANIAV, València: Editora UPV, Espanha, 2015, p.138-145.

DASH, Samir. UX Simplified. Models and methodologies. India: Digital Editions rights owned by PatternGraphic. First Edition, 2014

PREECE, Jennifer y ROGERS, Yvonne y SHARP, Helen: Design de interação - além da interação homem-computador. Porto Alegre: Bookman, 2005.

TEIXEIRA, Fabricio. Introdução e boas práticas em UX Design. São Paulo, Brasil: Casa do código, edição do Google Play Books, 2014.

Traducción del portugués al español: José Dario Vargas Parra. 